\title{
2 \\ Determination of Overflow Risk for Stormwater Systems
}

\section{Mathurin Daynou and Musandji Fuamba}

Stormwater systems (SWSs) are designed for "gravity flow" to convey stormwater runoff. The overflow risk appears when the design rainfall intensity is exceeded, i.e. when systems face rainfalls with short duration and/or high return periods. A two-module (hydrological and statistical) method is developed in this chapter to test the hydraulic performance for a SWS by determining its overflow risk.

The hydrological/hydraulic module selects the critical events: critical rainfalls series from a long recorded rainfall time series, runoff maximal flows (discharges), maximal velocities in conduits and flooding maximal volumes. Afterwards a series of frequency analyses is done with these critical values in the statistical module to determine the SWS overflow risk linked to the 5-, 10- 20-, 50-, and 100-y critical events.

The application of the proposed method to a case study of the Nuns' Island off the southeast shore of Montreal has shown that the overflow risk of the design storm (rainfall) is not negligible. The studied SWS presents a real flooding risk, depending on the selected time period.

\subsection{Introduction}

For decades, stormwater management had been viewed as political and quantitative; political, because management by nature involves political decisions; quantitative because of its targeted technical objective which is

Daynou, M. and M. Fuamba. 2008. "Determination of Overflow Risk for Stormwater Systems." Journal of Water Management Modeling R228-02. doi: 10.14796/JWMM.R228-02.

(C) CHI 2008 www.chijournal.org ISSN: 2292-6062 (Formerly in Reliable Modeling of Urban Water Systems. ISBN: 978-0-9808853-0-9) 
the fast conveyance of stormwater runoff. Thus, the design of drainage infrastructures mainly involved the determination of diameters, slopes, and invert elevations for each pipe in the system. Once a layout was selected, the design was finalized after the hydrologic and hydraulic steps were completed.

Increasingly, stormwater drainage design does not just involve pipe geometry, but also includes "green" considerations called "Best Optimal Practices (BOP)" such as pervious pavement, retention ponds/wetlands, green roofs, etc.

\subsubsection{Hydrology for SWSs Design}

The hydraulic design of a SWS requires estimation of peak runoff flow rates. Developed more than 100 years ago, the "Rational Method" is still a classic tool for estimating the peak runoff flow rate, also known as the design storm. When watersheds are large, it could be appropriate for hydrologic design to estimate the entire flow hydrograph using computer models such as SWMM5, HYMO and ILLUDAS (Anctil et al., 2005; Chow et al., 1988).

However the reliability of the designed SWS is unknown during its design stage although it is useful information for engineers and authorities. Furthermore, the capacity of SWS has become inadequate, causing massive street and basement flooding. An example is the grade-separated l'Acadie intersection in Montreal. The Meilleur-Atlantique sewer overflowed twice in summer 2005 (June 14 and July 6). Water suddenly increased over two meters under the viaduct. Because the flooding occurred in a highway underpass, only traffic circulation was affected. The potential for severe and costly damage from a similar extreme storm event in the nearby urban area would, however, be extremely high.

\subsubsection{Hydraulics for SWSs Design}

A continuous modeling approach is used for the SWSs design analysis by performing actual computer models (INFONET, SWMM5 and others software families) to easily evacuate all future rainstorm events that $d o$ not exceed the specified design hydrologic level. The latter is defined as related to a fixed overflow risk. The overflow risk appears when the design storm is exceeded, i.e. when systems face rainfalls with short duration or high return periods. The design storm is a precipitation pattern defined for use in the design of a hydrologic system. 
Therefore, the SWS overflow risk is fixed by the design storm which is defined by the used return period. The sizes of the system are determined in such a way that all rainstorms equal to and smaller than the design storm are presumably considered and accounted for. The minimum required diameter is computed and the next largest commercially available size is selected. The system is supposed to drain free-surface flow by gravity (Mays, 2001; Brière, 2000; Capart et al., 1997).

In recent years, urbanization and suspected climate change have resulted in increased peak flow rates, volume of runoff, frequency and severity of flooding and a corresponding decreased period of extremely heavy downpour (Chocat, 1997). Urban SWS also have been handling an increase in mixed flows during flooding periods. Mixed or transient flows are freesurface flows and full flows existing simultaneously. Due to their intensity, they could cause hydraulic failures, such as collapse of infrastructures, manhole cover blow off, geysers, and basement flooding.

To face this increase of flooding scenarios, many cities have decided to increase arbitrarily the rainfall return period in order to decrease the overflow risk. Attention has not been paid to the overflow risk analysis during the design process of new SWS. The present chapter analyzes the design process by including the overflow risk aspect resulting from the probability of exceedance of the design storm.

\subsection{Methodology}

The methodology used in this study has two steps: hydrological and statistical. The objective of the hydrological step is to identify all critical rainfalls responsible for street overflow. The objective of the statistical step is to determine the probability of exceedance of the design storm and the return periods of identified critical rainfalls. Hydraulic parameters such as maximal velocity and flow rate, as well as total flooding volume are also analyzed to determine the hydraulic performance of the studied SWS.

\subsection{Proposed Method}

SWSs are designed for "gravity flow" to convey stormwater runoff. The overflow risk appears when the design rainfall intensity is exceeded, i.e. when systems face rainfalls with short duration or high return periods. Unless exceptional events occur (whose intensity is greater than design 
storm), runoff from all contributing subcatchment areas is to be taken by the SWS without overloading the conduits. Additionally, all the hydrodynamic parameters (flow rates, velocities and water levels into transversal cross sections) should remain below the hydraulic capacity of the conduits.

The proposed method is developed to test the better functioning of an existing SWS, by estimating its capability to cope with the stormwater adequately (overflow risk). The method identifies during a given period all critical events which overload at least one conduit and overflow one manhole. The overflow risk is then evaluated in order to determine the hydraulic performance of the studied SWS. To do so, two calculation modules are developed: hydrological and statistical.

\subsubsection{Hydrological Module}

A hydrologic simulation is performed in this module as the response of a hydrologic water resource system to a series of events during a selected time period. This model is structured to simulate direct runoff hydrographs. A few of the SWS or runoff computer models for simulating rainfall-runoff events are available on the market: PCSWMM (James et al., 2005), INFONET (2007)...

Urban SWS models simulate the flow of stormwater in existing or designed systems with predetermined geometric sizes. They simulate the flow for a single rainfall event, but a few can simulate the response to a sequence of events. The simulation can be historical, real-time, or synthetically-generated storm events. Basic hydraulic notions are considered in most models. More and more models are now including water quality simulation. It may be noted that the purpose of flow simulation is to check the adequacy and performance of an existing and proposed system for flood mitigation and water pollution control, to provide useful information for storm water management, or to form part of a real-time operational control system (Chow et al., 1988).

The EPA Storm Water Management Model (SWMM5) is suggested in this module. The model is a dynamic rainfall-runoff simulation model used for single event or long-term (continuous) simulation of runoff quantity and quality from primarily urban areas. Developed in 1971, it has undergone several major upgrades and continues to be widely used all over the world for planning, analysis and design related to stormwater runoff, combined sewers, sanitary sewers, and other drainage systems in urban areas, with many applications in non-urban areas, as well (James et al., 2005). The runoff component of SWMM5 operates on a collection of subcatchment 
areas receiving precipitation and generating runoff and pollutant loads. The routing portion of SWMM5 transports this runoff through a system of pipes, channels, storage devices, pumps and regulators. SWMM5 tracks the quantity and quality of runoff generated within each subcatchment, and the flow rate, flow depth, and quality of water in each pipe and channel during a simulation period comprised of multiple time steps.

Where available, the historical rainfall series will be used to simulate the drainage system hydraulic performance, as well as the design rainfall. In order to limit the simulation time, the methodology proposed by Vaes and Berlamont (1999) for the choice of a short series of appropriate rainfalls is used in this study. In this case, the procedure to be used is the following:

1. simulation of the historical rainfall series in order to take into account the effects of the antecedent humidity conditions of the ground;

2. selection of critical events, whose rainfalls cause one or more overflowing scenarios;

3. simulation of each of the critical rainfalls in order to test the SWS hydraulic performance;

4. determination of the duration and intensity of the critical rainfalls; and

5. determination of the resulting flooding volume from each critical rainfall.

\subsubsection{Statistical Module}

Once all the critical rainfalls (hydrologic data) are identified, as well as hydraulic parameters (hydraulic data) like the maximal flow rate, velocity and flooding volume, it appears necessary to determine the probability of exceedance of the design rainfall in order to evaluate the SWS overflow risk. This can be achieved by a series of a frequency analysis series. The objective of the frequency analysis series is to relate the magnitude of extreme events (hydrologic and hydraulic data) to their frequency of occurrence through the use of probability distributions. Such analyses are performed by the statistical module implemented into the developed method. The procedure which is used by the present module is the following:

1. selection of the good fit probability distribution;

2. evaluation of the overflow risk or the probability of exceedance of the design storm; and

3. determination of the hydraulic response according to return periods. 
The hydrologic and hydraulic data should be independent, identically distributed and the hydrologic system producing them stochastic, spaceindependent, and time-independent in the classification scheme. Various statistical tests are being used to check the independence and the homogeneity of data series. Hydrologic and hydraulic data will be adjusted from the following typical probability distributions: Normal, (N), LogNormal (LN), Log-Normal type 3, Pearson type 3 (P3), Log-Pearson type 3 (LP3) and Extreme Value type 1 (EV1) (non exhaustive list). Table 2.A1 lists the used probability distributions and related fitting methods.

Numerous fitting methods are combined to the fitting of the probability distribution: method of moments (normal/weighted), method of maximum likelihood and estimation of quantiles $\mathrm{X}_{\mathrm{T}}$ of return period $\mathrm{T}$ with confidence intervals. The goodness of fit of any probability distribution will be tested by comparing the theoretical and sample values of the relative frequency function. A few tests can then be used such as $\chi^{2}$, Kolmogorov-Smirnov and Anderson-Darling. The primary advantage of the chi-square test is that it is quite general. It can be applied for any distribution, either discrete or continuous, for which the cumulative distribution function can be computed.

A routine has been developed under MatLab version 7.0.1, a high-level language and interactive environment that enables the performance of computationally intensive tasks (MathWorks, 2004). Input data needed in the routine are files of hydrological and hydraulic data series computed through the hydrological module. Statistical analyses are then performed by the use of the statistical module to select the best fit probability distribution, evaluate the overflow risk or the probability of exceedance of the design storm and determine the SWS hydraulic response according to some selected return periods: maximal flow rate, velocity and flooding volumes. The overflow risk $R$ represents the natural hydrological risk that a SWS designed for an event of a return period $T$ will have its capacity exceeded for $n$ years.

\subsection{Case Study}

\subsubsection{Description of the Selected SWS}

The minor SWS of Nuns' Island off the southeast shore of Montreal (see Figures 2.1 and 2.2) appears as an interesting case study: this drainage system is totally separated from the wastewater system and it's relatively recent even if constructed in 1968 . The island is $2 \mathrm{~km}$ long and $1.4 \mathrm{~km}$ wide, with 20,000 inhabitants. The covering area is relatively small and well 
identified when compared to the Island of Montreal watershed. The whole design documentation is available, except the island rainfall data.

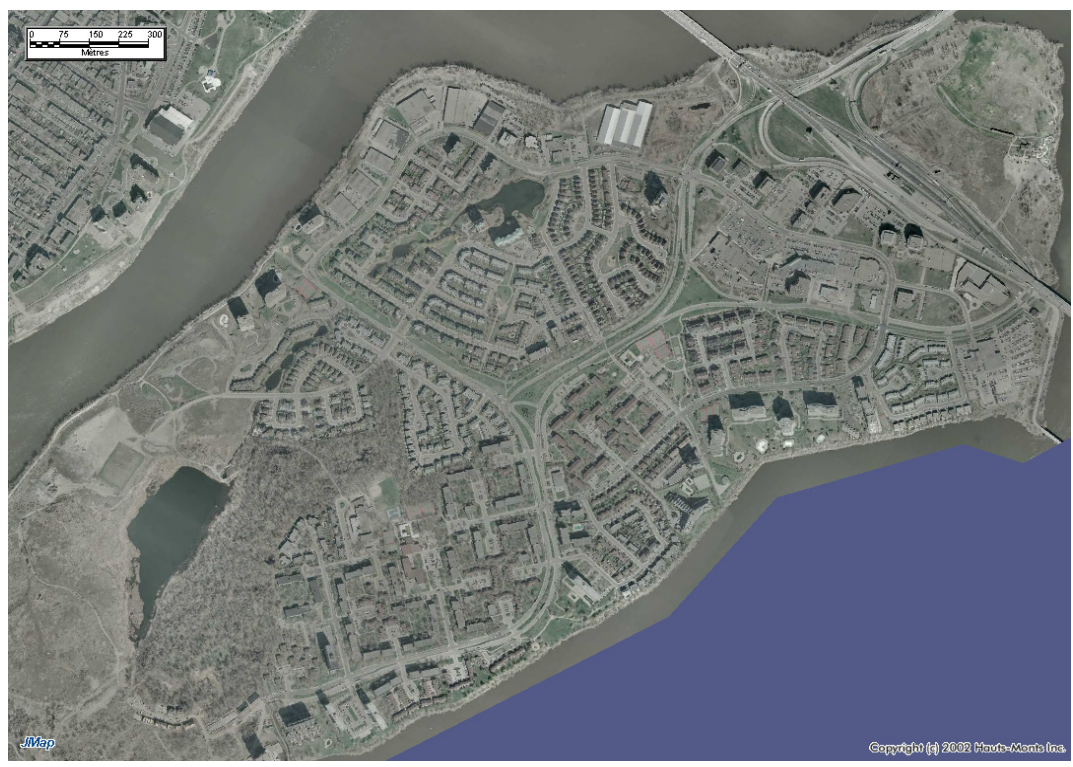

Figure 2.1 Aerial view of Nuns' Island off the southeast shore of Montreal.

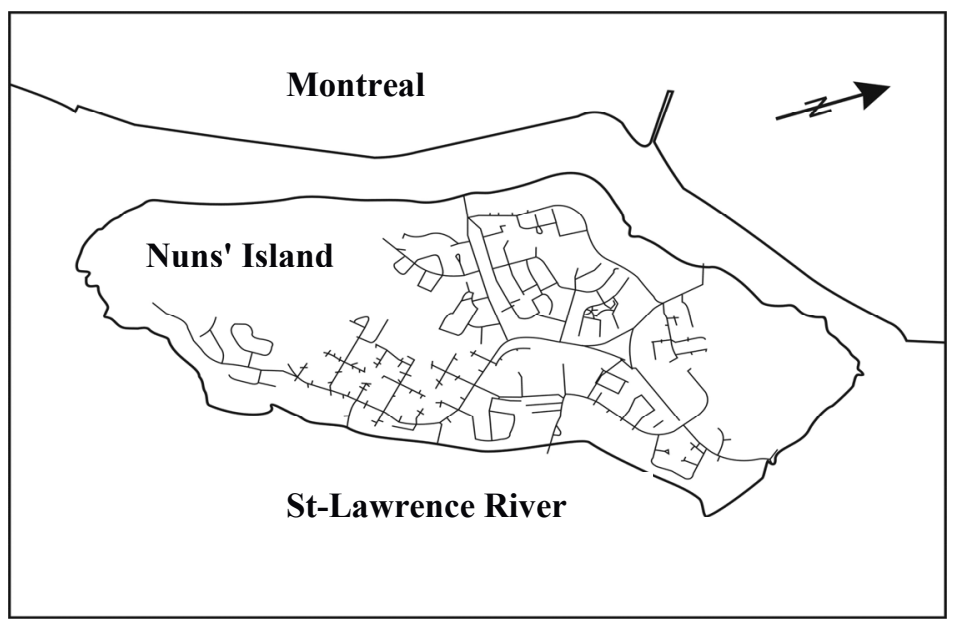

Figure 2.2 View of the SWS of Nuns' Island off the southeast shore of Montreal. 
The SWS was designed based on the Chicago storm. For the purpose of this study, the Chicago storm was reproduced. The 50-y historical rainfall series measured from the Dorval station (Montreal), was used in the study (Environment Canada, 2006). Unfortunately, the maximal values of the series are reduced because of the long hyetograph time step $(\Delta t=60 \mathrm{~min})$. The present study is still pertinent because of the general methodology developed to control the SWS hydraulic performance by determining the overflow risk.

EPA SWMM5 was used for modeling and simulating the hydrologic and hydraulic conditions of the SWS of Nuns' Island. Calibration of the model was done with the available documentation characterizing different subcatchment areas and runoff parameters (Verdun, 1998):

1. the impermeability rate was adjusted to $60 \%$ in dense residential sectors and between $20 \%$ and $60 \%$ in other sectors, depending on the nature of the sector;

2. the value of the Manning coefficient is fixed at 0.50 for pervious areas and 0.045 for the impervious areas. In conduits, the Manning coefficient has the value of 0.013 ;

3. the Horton's model of infiltration is used in the present study as it appears as the most-used model; and

4. the geometric characteristics of the SWS (lengths, slopes and diameters of conduits, elevations of manholes etc) are in accordance with the SWS of Nuns' Island 'As Built' drawings and available in the design documentation.

\subsubsection{Numerical Modeling of the SWS of Nuns' Island}

If $t$ is defined as the watershed concentration time, an equation defining the intensity-duration-frequency (IDF) curve in the Montreal region can be expressed by (Rivard, 2005):

$$
i_{I D F}=\frac{a}{(t+b)^{c}}
$$

Parameters $a, b$ and $c$, according to different return periods from $2-100 \mathrm{y}$, are listed in Table 2.2. These values are obtained from data measured at the Dorval station.

Once an equation defining the IDF curve for the Montreal region is known, an equation using the instantaneous intensity method can be developed for the variation of the intensity with time in the design 
hyetograph. If $t_{d}$ is the total duration of the rainfall, this equation represents the Chicago storm, which is expressed by (Musy, 2003):

$$
i_{\text {Chicago }}=\frac{a\left[(1-c) t_{d}+b\right.}{\left(t_{d}+b\right)^{c+1}}
$$

Defined as the time between intersections, $t_{d}$ can be expressed by:

Where:

$$
t_{d}=t_{a}+t_{b}
$$

$$
\begin{aligned}
& t_{a}=\text { the time of intersection before the peak, and } \\
& t_{b}=\text { the time after the peak. }
\end{aligned}
$$

The total duration of the rainfall $t_{d}$ can be expressed according to the storm advancement coefficient $r$, as the ratio of the time before the peak to the time between intersections:

$$
r=\frac{t_{a}}{t_{b}}
$$

According to Marsalek, quoted by Musy (2003), $r$ can take the value of 0.488 in Ontario. This value was extended to the Montreal region. The SWS computer model was calibrated with the Chicago storm, using the 5-y IDF curve. These parameters can be seen in Table 2.1.

Table 2.1 IDF Parameters for Montreal region (Rivard, 2005).

\begin{tabular}{ccccc}
\hline \multirow{2}{*}{$\begin{array}{c}\text { Return Period } \\
(\mathrm{y})\end{array}$} & $a(\mathrm{~mm} / \mathrm{h})$ & $b(\mathrm{~min})$ & $c$ & $r$ \\
\cline { 2 - 5 } & 657.204 & 5.273 & 0.806 & 0.488 \\
5 & 1121.542 & 7.507 & 0.856 & 0.488 \\
5 & 1562.794 & 9.094 & 0.892 & 0.488 \\
10 & 2134.165 & 10.501 & 0.921 & 0.488 \\
25 & 244.834 & 10.781 & 0.927 & 0.488 \\
50 & 2838.476 & 11.344 & 0.937 & 0.488 \\
\hline 100 & &
\end{tabular}

Validation of the model was done using the Chicago storm as the design rainfall. The value of $t_{d}$ was fixed at $420 \mathrm{~min}$, the average of all observed rainfalls in the historical rainfall series (Environment Canada, 2006). The used time step $\Delta t$ is $60 \mathrm{~min}$ (see paragraph 2.4.1). The Chicago storm used to calibrate the Nuns' Island SWS computer model is shown in Figure 2.3, where the maximal value of the hyetograph is $30.40 \mathrm{~mm} / \mathrm{h}$. 


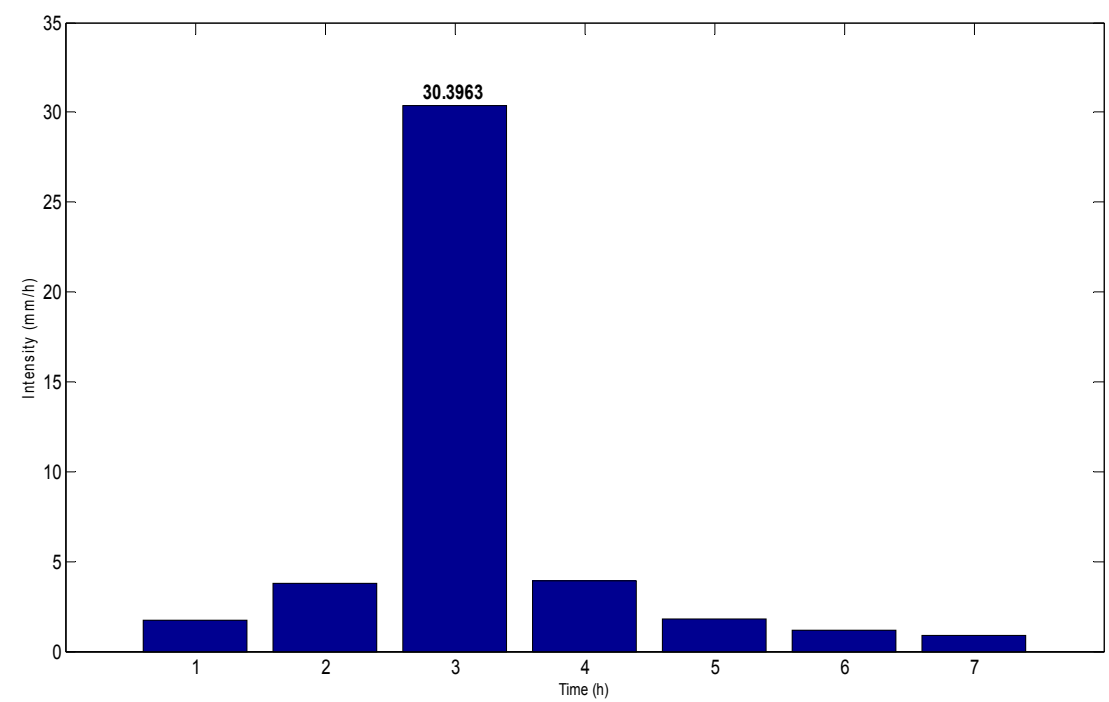

Figure 2.3 The 5-y 7-h design hyetograph for the Nuns' Island SWS.

\subsubsection{Hydrological and Hydraulic Results}

Numerical simulations of the Nuns' Island SWS have been conducted in the hydrological module by the use of EPA SWMM5. The 50-y historical rainfall series was used and hydraulic analyses have been done to identify all critical events causing at least one manhole overflow. Fifty events were identified. Each event was simulated individually in order to determine the SWS hydraulic responses: maximal runoff, flooding volumes or maximal velocity observed in the SWS. Results are presented in (Table 2.A2).

\subsubsection{Statistical Results}

Statistical analyses were conducted on hydrological and hydraulic data and obtained from paragraph 2.4.3 and two goodness fitting tests used: Chi-Square and Kolmogorov-Smirnov. These analyses indicated that the Log-Normal Type 3 distribution adjusts best to all the samples of analyzed data in the confidence interval of $95 \%$ (Table 2.2 and Figure 2.4). If $T$ and $n$ represent the return and exceedance periods respectively, the overflow risk $R$ can be calculated by

$$
R=1-\left(1-\frac{1}{T}\right)^{n}
$$


Table 2.2 Results from the two used goodness fitting tests: Chi-Square and Kolmogorov-Smirnov.

\begin{tabular}{|c|c|c|c|c|c|c|c|c|c|c|c|c|c|}
\hline \multirow{2}{*}{$\begin{array}{l}\text { Distributions : } \\
\text { variables : }\end{array}$} & & \multicolumn{4}{|c|}{ Normal } & \multicolumn{4}{|c|}{ Log-Normal } & \multicolumn{4}{|c|}{ Log-Normal Type 3} \\
\hline & & $\mathbf{P}_{\max }$ & $\mathbf{Q}_{\max }$ & $\mathbf{V}_{\max }$ & $\mathrm{Vol}_{\max }$ & $\mathbf{P}_{\max }$ & $\mathbf{Q}_{\max }$ & $\mathbf{V}_{\max }$ & $\mathrm{Vol}_{\text {in }}$ & $\mathbf{P}_{\max }$ & $\mathbf{Q}_{\max }$ & $\mathbf{V}_{\max }$ & $\mathrm{Vol}_{\text {max }}$ \\
\hline \multirow{2}{*}{ Kolmogorov-Smirnov } & Result: & 0 & 0 & 0 & 1 & 0 & 0 & 0 & 0 & 0 & 0 & 0 & 0 \\
\hline & p-value: & 0.12 & 0.08 & 0.23 & 0.00 & 0.41 & 0.39 & 0.35 & 0.93 & 0.71 & 0.58 & 0.53 & 0.75 \\
\hline \multirow{2}{*}{ Chi-square } & result: & & 1 & 0 & 1 & 0 & 0 & 0 & 0 & 0 & 0 & 0 & 0 \\
\hline & p-value: & 0.08 & 0.02 & 0.21 & 0.00 & 0.43 & 0.55 & 0.60 & 0.88 & 0.30 & 0.91 & 0.67 & 0.63 \\
\hline Pmax $=$ Max.. Precipitations & & \multicolumn{4}{|c|}{$Q_{\max }$ maximal discharge } & \multicolumn{4}{|c|}{$V_{\max }:$ maximal flow velocity } & \multicolumn{4}{|c|}{ Vol $_{\max }=$ Total flooding } \\
\hline \multirow{2}{*}{$\begin{array}{l}\text { Distributions : } \\
\text { variables : }\end{array}$} & & \multicolumn{4}{|c|}{ Pearson Type 3} & \multicolumn{4}{|c|}{ Log-Pearson Type 3} & \multicolumn{4}{|c|}{ Extreme Value Type 1} \\
\hline & & $\mathbf{P}_{\max }$ & $\mathbf{Q}_{\max }$ & $\mathbf{v}_{\max }$ & $\mathrm{Vol}_{\text {in }}$ & $\mathbf{P}_{\max }$ & $\mathbf{Q}_{\max }$ & $\mathbf{V}_{\max }$ & $\mathbf{V o l}_{\text {in }}$ & $\mathbf{P}_{\max }$ & $\mathbf{Q}_{\max }$ & $\mathbf{V}_{\max }$ & $\mathbf{V o l}_{\max }$ \\
\hline \multirow{2}{*}{ Kolmogorov-Smirnov } & Result: & 0 & 0 & 0 & 0 & 0 & 0 & 1 & 0 & 1 & 1 & 1 & 1 \\
\hline & p-value: & 0.32 & 0.27 & 0.33 & 0.08 & 0.52 & 0.44 & 0.00 & 0.74 & 0.00 & 0.00 & 0.01 & 0.00 \\
\hline \multirow{2}{*}{ Chi-square } & Result: & & 0 & 0 & 1 & 0 & 0 & 0 & 0 & 1 & 1 & 0 & 1 \\
\hline & p-value: & 0.18 & 0.11 & 0.27 & 0.00 & 0.52 & 0.64 & 0.62 & 0.76 & 0.01 & 0.00 & 0.01 & 0.00 \\
\hline
\end{tabular}
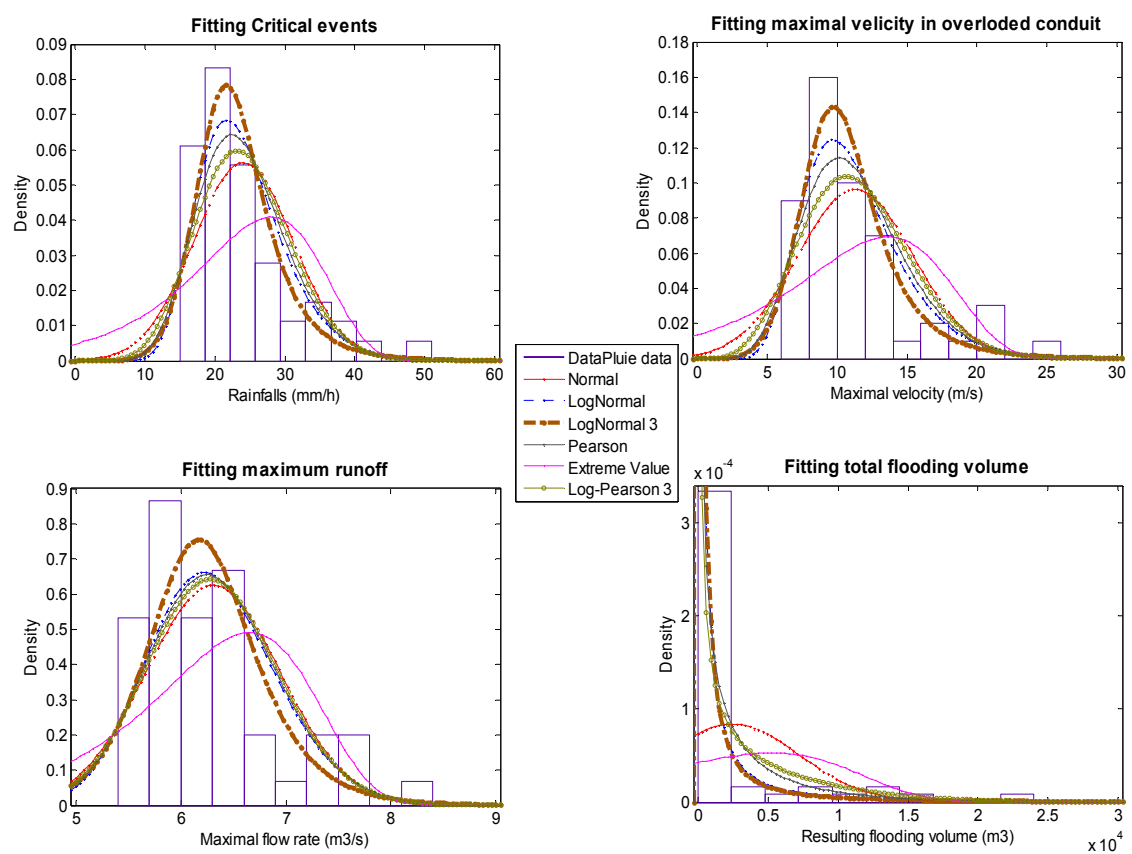

Figure 2.4 Graphic overview of obtained results from the goodness fitting analyses. 
Results from the good fit (Log-Normal Type 3) are presented hereafter under the graphic form (Figure 2.5) and the table form (Table 2.3). All different adjustments allow a link between the SWS hydraulic performance and every selected return period. The SWS hydraulic performance is measured by the overflow risk, maximal velocity and flooding volume that the SWS is facing. Figure 2.5 indicates a value of rainfall, maximal velocity, runoff flow rate and flooding volume associated with each selected return period (or probability of occurrence). This means that it becomes possible for the SWS designers or managers to link some fixed targets and objectives (overflow risk, total flooding volume ...) to their frequency of appearance, according to the local historic rainfall series.
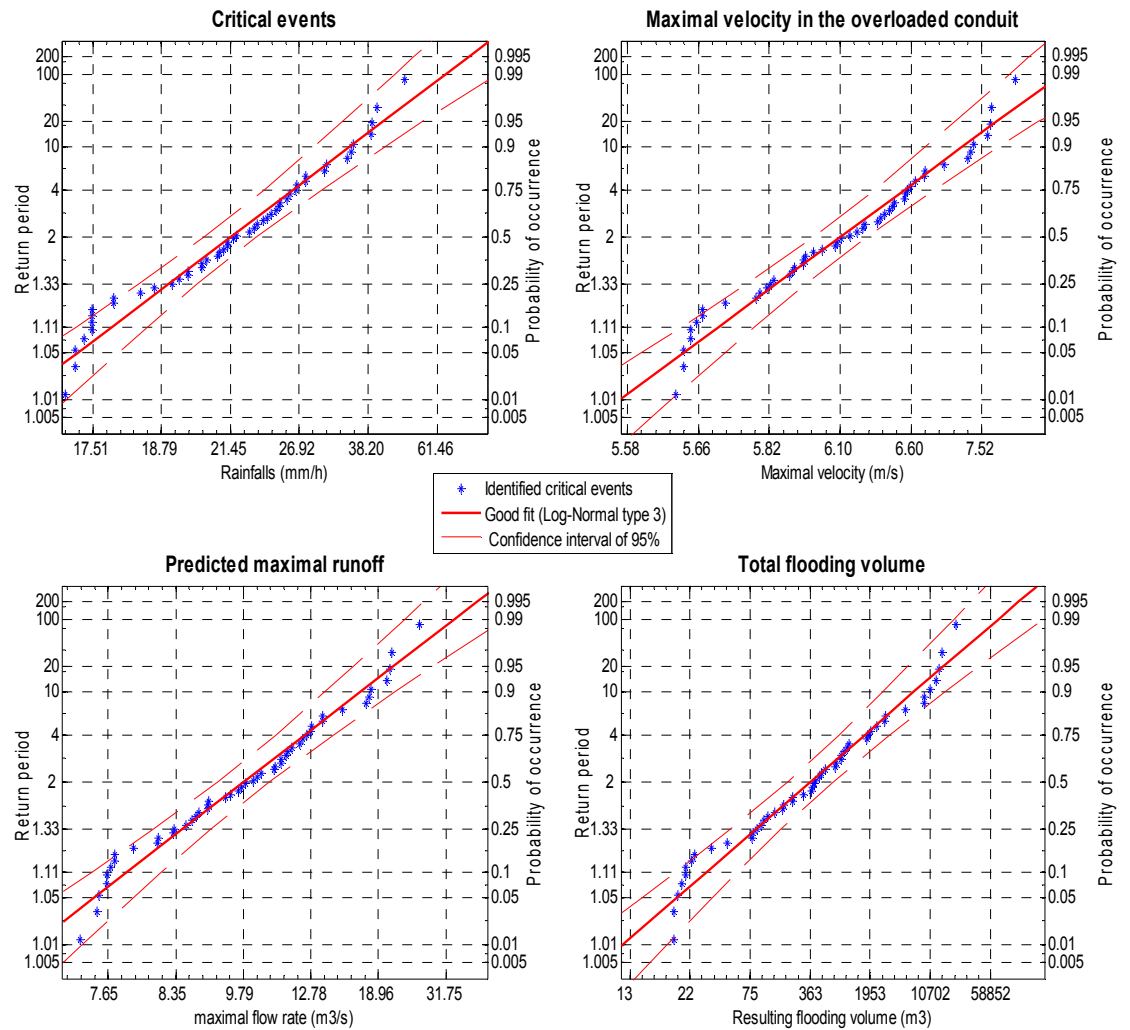

Figure 2.5 Graphic overview of obtained results for the Nuns' Island SWS.

Knowledge of the local topography makes it possible to predict the flooding zone and quantify human and financial damages induced by the 
resulting flooding volume. Complementary solutions to classical drainage solutions can be then planed to supply minor SWSs and avoid the eventual damages to residents and the riverside environment.

Table 2.2 shows the linkage between the return period and the SWS overflow risk in a period of 5-20 y For example, the overflow risk of the $10-\mathrm{y}$ return period rainfall of $34.33 \mathrm{~mm} / \mathrm{h}$ is $65 \%$ over a period of $10 \mathrm{y}$ and $88 \%$ if the period is 20 y The overflow risk seems higher even if the $10-y$ rainfall is only $3 \mathrm{~mm} / \mathrm{h}$ higher than the design rainfall. The resulting maximal flow rate is $7.21 \mathrm{~m}^{3} / \mathrm{s}$. It generates into the SWS a maximal velocity of $16.78 \mathrm{~m} / \mathrm{s}$ and a flood volume of $6679 \mathrm{~m}^{3}$. The velocity value is more critical because of the potential erosion it will cause in conduits.

Table 2.3 Overflow risk linked to return periods for the Nuns' Island SWS.

\begin{tabular}{lcccccccc}
\hline Rainfall Return Period (year) & $\mathbf{2}$ & $\mathbf{5}$ & $\mathbf{1 0}$ & $\mathbf{1 5}$ & $\mathbf{2 0}$ & $\mathbf{2 5}$ & $\mathbf{5 0}$ & $\mathbf{1 0 0}$ \\
\hline 5-year overflow risk (\%) & - & - & 41 & 29 & 23 & 18 & 10 & 5 \\
10-year overflow risk (\%) & - & - & 65 & 50 & 40 & 34 & 18 & 10 \\
20-year overflow risk (\%) & - & - & 88 & 75 & 64 & 56 & 33 & 18 \\
Exceedance probability (\%) & 50 & 20 & 10 & 7 & 5 & 4 & 2 & 1 \\
$\mathrm{P}_{\max }(\mathrm{mm} / \mathrm{h})$ & 21.45 & 27.99 & 34.23 & 37.96 & 41.83 & 44.6 & 54.3 & 65.83 \\
$\mathrm{Q}_{\max }\left(\mathrm{m}^{3} / \mathrm{s}\right)$ & 6.1 & 6.7 & 7.21 & 7.51 & 7.8 & 8.01 & 8.7 & 9.49 \\
$\mathrm{~V}_{\max }(\mathrm{m} / \mathrm{s})$ & 9.79 & 13.36 & 16.78 & 18.82 & 20.95 & 22.47 & 27.8 & 34.16 \\
$\mathrm{Vol}_{\max }\left(\mathrm{m}^{3}\right)$ & - & - & 6679 & 10419 & 15348 & 19559 & 39176 & 73185 \\
\hline
\end{tabular}

\subsection{Conclusion and Recommendation}

Flooding is occurring more and more in our time and it appears that the SWS hydraulic performance has to be frequently tested in order to insure the proper functioning of the drainage planning. Testing the drainage systems implies determining the overflow risk and the probability of exceeding the design storm. A diagnostic method has been presented in this chapter to evaluate the SWS hydraulic performance.

The proposed method has two modules: hydrological and statistical. The hydrologic unit transforms the historical rainfall series into runoff and allows identifying the critical events responsible for at least one manhole overflow. The statistical unit allows determining the good fit of the critical hydrological events as well as resulting critical hydraulic parameters that would decrease the SWS hydraulic performance. 
The application of the proposed method to a case study selected for Nuns' Island off the southeast shore of the Montreal region indicates that the overflow risk really exists. The SWS designers and managers can use the presented tool to anticipate more accurately the possible damages induced by potential flooding scenarios. Predicted results could help to implement more innovative and sustainable solutions, complementary to classical ones, when facing the stormwater management. The proposed method needs more refinement in the use of the historical rainfall series with relative short time steps $(\Delta t=5-15 \mathrm{~min})$ in order to work with feasible maximal hyetograph values.

\section{Acknowledgments}

The authors would like to acknowledge CERIU (Centre de Recherches en Infrastructures Urbaines) and the Borough of Verdun (Montreal, Quebec, Canada) for their contributions to this project.

\section{References}

Anctil, F., Rousselle J., and Lauzon N. 2005. Hydrologie-cheminement de l'eau. Presses Internationales Polytechnique, Montreal, Canada.

Brière, F.G. 2000. Distribution et collecte des eaux, deuxième édition. Presses internationales Polytechnique. Montréal, Canada.

Capart, H., Sillen X., and Zech, Y. 1997. Numerical and Experimental Water Transients in Sewer Pipes. Journal of Hydraulic Research, 35(5): 659-672.

Chocat, B. (1997). Encyclopédie de l'hydrologie urbaine et de l'assainissement. Londres, Lavoisier Tec \& Doc.

Chow, V.T., Maidment, D.R., and Mays, L.W. 1988. Applied Hydrology. McGraw-Hill Book Company, New York, USA.

Environnement Canada 2006. Données de pluie à la station météorologique de Dorval. Montreal, Canada.

INFONET, 2007. Asset and data management system for water networks - water supply, water distribution, wastewater collection, sewers and storm water. On-line documentation: Web site http://www.wallingfordsoftware.com/products/infonet/ Oxfordshire, UK.

James, W., Huber, W.C., Rossman, L.A., Dickinson, R.E., Pitt, R.E., James, R.C., Roesner, L.A., and Aldrich, J.A. 2005. Storm Water Management Model (PCSWMM) - Version 5: User's guide to SWMM. Computational Hydraulics International (CHI), Guelph, Ontario, Canada. 
MathWorks 2004. MatLab-The language of technical computing; Version 7, The MathWorks, Inc.3 Apple Hill Drive Natick, MA 01760-2098

Mays, L.W. 2001. Storm Collection Systems Design Handbook, McGraw-Hill, USA.

Musy, A. 2003. Hydrologie appliquée. Cours polycopié à l'intention des étudiants de la Faculté ENAC, École Polytechnique Fédérale de Lausanne, Switzerland.

Rivard, G. 2005. Gestion des eaux pluviales en milieu urbain. Alias Communication Design, Laval, Québec, Canada.

Vaes, G. and Berlamont, J. 1999. Selection of appropriate short rainfall series for design of combined sewer systems. University of Leuven, Hydraulic Laboratory, Belgium.

Verdun 1998. Plan directeur d'égout sanitaire, d'égout pluvial et d'aqueduc pour la pointe sud de l'Île-des-Sœurs. Rapport préparé par le Groupe-conseil Genivar inc., Montreal, Canada.

\section{Appended Tables}

Table 2.A1 Probability distributions for fitting hydrologic data (from Chow et al. 1988).

\begin{tabular}{|c|c|c|c|}
\hline Distribution & Probability density function & Range & $\begin{array}{c}\text { Equations for parameters in terms of the } \\
\text { sample moments }\end{array}$ \\
\hline Normal & $f(x)=\frac{1}{\sigma \sqrt{2 \pi}} \exp \left(-\frac{x-\mu)^{2}}{2 \sigma^{2}}\right)$ & $-\infty \leq x \leq \infty$ & $\mu=x_{\text {median }}, \sigma=s_{x}$ \\
\hline $\begin{array}{c}\text { Log-Normal } \\
(\text { where } y=\log x)\end{array}$ & $f(x)=\frac{1}{x \sigma \sqrt{2 \pi}} \exp \left(\frac{-\left(y-\mu_{y}\right)^{2}}{2 \sigma_{y}^{2}}\right)$ & $x>0$ & $\mu_{y}=y_{\text {median }}, \sigma_{y}=s_{y}$ \\
\hline $\begin{array}{l}\text { Log-Normal Type } 3 \\
(\text { where } y=\log (x-\varepsilon))\end{array}$ & $f(x)=\frac{1}{x \sigma \sqrt{2 \pi}} \exp \left(\frac{-\left(y-\mu_{y}\right)^{2}}{2 \sigma_{y}^{2}}\right)$ & $x \geq \varepsilon$ & $\varepsilon \approx \frac{x_{1} x_{2}-x_{\text {median }}^{2}}{x_{1}+x_{2}-2 x_{\text {median }}}$ \\
\hline Pearson Type 3 & $f(x)=\frac{\lambda^{\beta}(x-\varepsilon)^{\beta-1} e^{-\lambda(x-\varepsilon)}}{\Gamma(\beta)}$ & $x \geq \varepsilon$ & $\lambda=\frac{s_{x}}{\sqrt{\beta}}, \beta=\left(\frac{2}{C_{s}}\right)^{2}, \varepsilon=x_{\text {median }}-s_{x} \sqrt{\beta}$ \\
\hline $\begin{array}{c}\text { Log-Pearson Type } 3 \\
(\text { where } y=\log x)\end{array}$ & $f(x)=\frac{\lambda^{\beta}(y-\varepsilon)^{\beta-1} e^{-\lambda(y-\varepsilon)}}{x \Gamma(\beta)}$ & $\log x \geq \varepsilon$ & $\lambda=\frac{s_{y}}{\sqrt{\beta}}, \beta=\left[\frac{2}{C_{s}(y)}\right]^{2}, \varepsilon=y_{\text {median }}-s_{y} \sqrt{\beta}$ \\
\hline $\begin{array}{l}\text { Extreme Value } \\
\text { (Type 1) }\end{array}$ & $f(x)=\frac{1}{\alpha} \exp \left[-\frac{x-u}{\alpha}-\exp \left(-\frac{x-u}{\alpha}\right)\right]$ & $-\infty<x<\infty$ & $\alpha=\frac{\sqrt{6} s_{x}}{\pi}, u=x_{\text {median }}-0.5772 \alpha$ \\
\hline
\end{tabular}


Tableau 2.A2 Fifty critical events identified and resulting hydraulic parameters.

\begin{tabular}{|c|c|c|c|c|c|c|c|c|c|}
\hline Date & $\begin{array}{c}\mathbf{P}_{\max } \\
(\mathrm{mm} / \mathrm{h})\end{array}$ & $\begin{array}{c}\mathbf{Q}_{\max } \\
\left(\mathrm{m}^{3} / \mathrm{s}\right)\end{array}$ & $\begin{array}{l}\mathbf{V}_{\max } \\
(\mathrm{m} / \mathrm{s})\end{array}$ & $\begin{array}{c}\mathbf{V o l}_{\max } \\
\left(\mathrm{m}^{3}\right)\end{array}$ & Date & $\begin{array}{c}\mathbf{P}_{\max } \\
(\mathrm{mm} / \mathrm{h})\end{array}$ & $\begin{array}{c}\mathbf{Q}_{\max } \\
\left(\mathrm{m}^{3} / \mathrm{s}\right)\end{array}$ & $\begin{array}{l}\mathbf{V}_{\max } \\
(\mathrm{m} / \mathrm{s})\end{array}$ & $\begin{array}{c}\mathbf{V o l}_{\text {max }} \\
\left(\mathrm{m}^{3}\right)\end{array}$ \\
\hline 09/01/82 & 17.8 & 8.109 & 5.776 & 80 & $07 / 16 / 76$ & 17.8 & 7.855 & 5.708 & 44 \\
\hline $07 / 02 / 75$ & 34 & 17.432 & 7.298 & 9070 & $08 / 16 / 66$ & 38.9 & 20.06 & 7.62 & 12711 \\
\hline $08 / 03 / 75$ & 21.8 & 10.114 & 6.148 & 474 & $06 / 17 / 52$ & 30.2 & 12.74 & 6.547 & 935 \\
\hline 08/0389 & 16.9 & 7.36 & 5.57 & 8 & $06 / 18 / 84$ & 20.9 & 9.64 & 6.07 & 422 \\
\hline $07 / 04 / 51$ & 19.8 & 8.008 & 5.772 & 15 & 07/18/87 & 24.2 & 11.51 & 6.44 & 1062 \\
\hline $09 / 04 / 66$ & 17.5 & 7.7 & 5.67 & 24 & $06 / 19 / 75$ & 17.5 & 7.667 & 5.656 & 21 \\
\hline $07 / 05 / 58$ & 17.5 & 7.64 & 5.65 & 19 & 08/20/89 & 35 & 18.09 & 7.39 & 10781 \\
\hline $08 / 05 / 81$ & 25 & 12.133 & 6.543 & 1754 & $06 / 21 / 49$ & 26.7 & 11.727 & 6.464 & 722 \\
\hline $08 / 05 / 88$ & 17.3 & 7.58 & 5.64 & 20 & $06 / 21 / 61$ & 15.5 & 7.01 & 5.41 & 12 \\
\hline $06 / 06 / 63$ & 40.4 & 20.88 & 7.7 & 14778 & $07 / 21 / 64$ & 19.3 & 8.67 & 5.89 & 178 \\
\hline $08 / 06 / 65$ & 19.6 & 8.9 & 5.94 & 227 & $08 / 21 / 52$ & 24.6 & 10.947 & 6.231 & 405 \\
\hline $08 / 06 / 68$ & 23.1 & 10.9 & 6.33 & 862 & $07 / 22 / 60$ & 23.9 & 11.4 & 6.42 & 1003 \\
\hline $08 / 06 / 86$ & 17.4 & 7.64 & 5.65 & 89 & $07 / 23 / 74$ & 23.6 & 11.193 & 6.381 & 851 \\
\hline $07 / 07 / 58$ & 17.3 & 7.58 & 5.63 & 18 & $10 / 23 / 59$ & 27.7 & 13.56 & 6.75 & 2975 \\
\hline $09 / 07 / 69$ & 48.5 & 25.61 & 8.18 & 22277 & $06 / 24 / 62$ & 27.7 & 13.55 & 6.74 & 2960 \\
\hline $06 / 08 / 87$ & 34.7 & 17.78 & 7.34 & 8878 & $08 / 24 / 88$ & 21.3 & 9.87 & 6.1 & 552 \\
\hline $07 / 09 / 74$ & 19.1 & 8.613 & 5.879 & 172 & $06 / 25 / 57$ & 24.9 & 11.189 & 6.354 & 496 \\
\hline 08/09/59 & 21.1 & 9.73 & 6.08 & 384 & $07 / 25 / 62$ & 16.8 & 7.41 & 5.55 & 10 \\
\hline $07 / 10 / 66$ & 17.5 & 7.7 & 5.67 & 23 & $06 / 26 / 43$ & 20.1 & 8.311 & 5.805 & 21 \\
\hline $08 / 12 / 48$ & 20.1 & 8.499 & 5.831 & 32 & $07 / 26 / 73$ & 18.3 & 8.122 & 5.787 & 99 \\
\hline $09 / 12 / 63$ & 21.3 & 10.38 & 6.24 & 743 & $07 / 26 / 93$ & 17.1 & 7.47 & 5.6 & 13 \\
\hline $08 / 13 / 56$ & 22.6 & 9.43 & 5.972 & 140 & $08 / 26 / 61$ & 16 & 7.3 & 5.5 & 5 \\
\hline $06 / 14 / 67$ & 25.9 & 12.51 & 6.6 & 1993 & $08 / 26 / 70$ & 39.1 & 20.58 & 7.68 & 13861 \\
\hline $07 / 14 / 75$ & 19.6 & 8.896 & 5.934 & 226 & $06 / 27 / 94$ & 26.5 & 12.86 & 6.65 & 2313 \\
\hline 07/14/87 & 17 & 7.41 & 5.6 & 13 & $08 / 27 / 73$ & 30.5 & 15.138 & 6.972 & 5312 \\
\hline $08 / 14 / 84$ & 17.2 & 7.48 & 5.63 & 18 & $06 / 28 / 43$ & 20.8 & 8.727 & 5.902 & 78 \\
\hline $06 / 15 / 43$ & 21.6 & 8.928 & 5.928 & 106 & $06 / 28 / 57$ & 22.9 & 10.246 & 6.188 & 375 \\
\hline $07 / 15 / 63$ & 20.3 & 9.3 & 6.01 & 303 & $08 / 30 / 91$ & 25.6 & 12.31 & 6.57 & 1798 \\
\hline $08 / 15 / 61$ & 17.3 & 7.59 & 5.64 & 18 & 08/31/80 & 18.6 & 8.322 & 5.82 & 117 \\
\hline
\end{tabular}

